\title{
Reliability and Validity of the Korean World Health Organization Quality of Life (WHOQOL)- BREF in People With Physical Impairments
}

\author{
Wan Ho Kim, $\mathrm{MD}^{1}$, Soo Jung Hahn, $\mathrm{MD}^{1}$, Hyun Jeong Im², Kyung Soon Yang ${ }^{2}$ \\ Departments of ${ }^{1}$ Rehabilitation Medicine and ${ }^{2}$ Community Based Rehabilitation, National Rehabilitation Center, Seoul, Korea
}

Objective To identify the validity and reliability of the Korean version World Health Organization Quality of Life Assessment (WHOQOL)-BREF among people with physical impairments living in a community.

Methods Participants listed in the community-based rehabilitation project were recruited from 45 public health centers. People with brain lesions or physical disabilities were selected. Respondents $(n=750)$ filled out the Korean WHOQOL-BREF questionnaire. Obtained data were analyzed statistically to assess the internal consistency as well as the construct and discriminant validity. An exploratory factor analysis was also performed.

Results Cronbach's $\alpha$ for the total score was 0.839 . The value for each domain ranged from 0.746 to 0.849 . Pearson correlation coefficient between each domain ranged from 0.539 to 0.717 . The highest correlation was between the psychological and physical domain. The item-domain correlation indicated a significant correlation with their original domains. A multiple regression analysis of each domain with two overall questions was performed. The psychological domain made the strongest contribution with the overall quality of life (unstandardized coefficient $\mathrm{B}=0.065, \mathrm{r}^{2}=0.437$ ). When general health satisfaction was considered as a dependent variable, the physical domain most strongly contributed to the variable (unstandardized coefficient $B=0.081, r^{2}=0.462$ ). Exploratory factor analysis yielded four factors in the WHOQOL-BREF, accounting for $55.29 \%$ of the variability. To assess the discriminant validity, a comparison of each domain with Modified Barthel Index (MBI) was conducted. There were highly significant changes across the MBI scores with the WHOQOL-BREF domains $(\mathrm{p}<0.001)$.

Conclusion Korean WHOQOL-BREF is a valid and reliable tool to measure the quality of life for people with physical impairments. It has good internal consistency, construct validity and discriminant validity for the population. Further study with a stratified sample is needed.

Keywords WHOQOL-BREF, Community based rehabilitation, Reliability, Validity

(c) This is an open-access article distributed under the terms of the Creative Commons Attribution Non-Commercial License (http://creativecommons.org/ licenses/by-nc/3.0) which permits unrestricted noncommercial use, distribution, and reproduction in any medium, provided the original work is properly cited. Copyright $\odot 2013$ by Korean Academy of Rehabilitation Medicine 


\section{INTRODUCTION}

The number of people with disabilities is rapidly increasing in Korea. By December 2010, the Ministry of Health and Welfare registered 2,517,312 people as disabled [1]. The disabled population constructs $5.0 \%$ of the total population. Due to improvements in the living standard and public welfare system, the disabled population registered in Korean health care system is steadily increasing. The $96.5 \%$ of the total disabled population resides within communities [2]. Therefore, a communitybased rehabilitation (CBR) strategy is receiving more attention as there is an increased demand for the healthcare of people with disabilities.

For an initial assessment of people with disabilities, measuring their functional ability and quality of life is important. These measurements are also necessary for goal setting as well as for evaluating the effect of medical treatment. To assess the health-related quality of life, a Medical Outcome Study 8-items Short-Form Health Survey (SF-8) was first used in Korea's CBR project. The ease and quickness of administration are the most attractive aspects of SF-8 [3]. In a previous survey for people with disabilities living in Goyang city, the average score was 36 [2]. However, SF-8 could not reflect the detailed quality of life because there were only a few numbers of questions regarding the psychological, social and environmental aspect. Moreover, the SF-8 is not translated and validated for use on the Korean population. For this reason, a new scale is necessary to assess the quality of life among people with disabilities.

The World Health Organization Quality of Life Assessment (WHOQOL) is a self-reporting multidimensional measure which is composed of six domains: physical, psychological, levels of independence, social relationship, environment, and spirituality $[4,5]$. The shorter version WHOQOL-BREF (the abbreviated version of WHOQOL instrument) was therefore developed in order to enable a brief but accurate assessment of the quality of life [6]. The WHOQOL-BREF contains one item from each of the 24 facets of the quality of life included in the WHOQOL-100, plus two 'benchmark' items from the general facet on the overall quality of life and general health [7-9].

The Korean version of WHOQOL-BREF was developed in 2002. The results suggest that the Korean version WHOQOL-BREF is valid and reliable for assessing the quality of life [6]. With this method, the issue of searching a new tool for assessing the quality of life among people with disabilities could be satisfied; Korean WHOQOLBREF could be the substitute of SF-8.

The type of impairment is divided into four big sections: physical, sensory, mental (psychiatric), and intellectual. Chronic health conditions encountering difficulties in everyday life are also included in the boundary of disabilities $[10,11]$. Various segmented disability types are established by each government policy. There are fifteen types of disability in Korea, including internal organ impairment which is divided into six disability types.

We aim to search the usefulness of a new tool among people of various health conditions, such as stroke, traumatic brain injuries, amputees, spinal cord injuries, or other diverse physical impairment associated with musculoskeletal disorders. Such health conditions common in rehabilitation medicine unit could be broadly combined with the category of physical impairment. By subdividing, the physical impairment category would lead to a group of people who are registered with brain lesions or physical disabilities.

The aim of this study is to identify the validity and reliability of the Korean version WHOQOL-BREF among people with physical impairment living in communities.

\section{MATERIALS AND METHODS}

\section{Procedure and subjects}

Participants listed in the CBR project were recruited from 45 public health centers. People from randomized selected communities registered with brain lesions or physical disabilities were invited to complete our questionnaires. Respondents who had multiple disabilities related to physical impairment were included. Those excluded from the study were people with severe communication impairment who had difficulty completing the questionnaire despite assistance.

Subjects who agreed to participate in the study were requested to sign the consent form. The questionnaire was composed of questions related to health care status, satisfaction score, functional ability, and quality of life. The questionnaires were completed from November 15-26, 2009. A total of 994 respondents were initially included. With the exception of 244 respondents who had incomplete data, a statistical analysis was performed on the 
data of 750 respondents.

\section{Measurement}

Socio-economic personal information was obtained with regards to age, gender, marriage status, dwelling patterns, economic status, onset of impairment, and the type of registered disability.

For assessing the respondent's functional ability, the Korean version of Modified Barthel Index (K-MBI) was rated by health care providers working on the CBR project. The MBI consists of 10 items: personal hygiene, bathing, feeding, toileting, stair climbing, dressing, bowel control, bladder control, ambulation or wheelchair, and chair-bed transfer [12]. The item scores range from ' 0 ', which indicates an inability to perform, to a total score of 100 , which indicates a complete independence in selfcare performance [13].

MBI scores were divided into three groups, indicating the respondents' functional ability: 'total or severe dependence', 'moderate dependence', and 'slight or no dependence.' In the original Barthel Index, a total score of 0-20 suggests total dependence, 21-60 severe dependence, 61-90 moderate dependence, and 91-99 slight dependence [14]. However, this division has not been used widely in the MBI score system. A number of valued studies used different categories of disability on the Barthel Index [15-17]. After much consideration, we have decided to follow the Korean disability rating system standard of brain lesions, representing grade I-II, III-IV, and V-VI; each group indicates a MBI total score ' $0-53$,' ‘54-80', and '81-100'.

The WHOQOL-BREF is a 26 -item generic questionnaire containing four domains: physical health, psychological, social relationships, and environmental. Each domain includes three to eight items [18]. The first item (Q1) asks the overall quality of life, and the second item (Q2) asks questions on general health satisfaction. Each item is based upon a self-report using a 5-point scale, which is applied in all questions. Respondents then check one of the following degrees-'not at all,' 'a little', 'moderately', 'mostly', and 'completely' [6]. Higher scores indicate higher quality of life, with the exception of three negative forms which include pain and discomfort, need for medical treatment, and negative feelings [5]. Items proposed in negative form are calculated by subtracting the score form $6[6]$.

\section{Statistical analysis}

Obtained data were analyzed using SPSS ver. 14.0 (SPSS Inc., Chicago, IL, USA). In order to assess the reliability, the internal consistency of each domain was calculated using Cronbach's $\alpha$. Instruments with Cronbach's $\alpha$ value of 0.70 or greater are considered to have satisfactory internal consistency [18].

To examine the construct validity, intercorrelation between item-domain and factor analysis were conducted. Domain to domain and item to domain intercorrelation was analyzed by calculating Pearson product moment correlation coefficient. Correlations were interpreted as follows: $0.75 \leq \mathrm{r} \leq 1.0$, good; $0.50 \leq \mathrm{r}<0.75$, moderate; $0.25 \leq \mathrm{r}<0.50$, fair; and $0.00 \leq \mathrm{r}<0.25$, slight or none [18]. Stepwise multiple regression analyses were conducted in order to determine which WHOQOL domains best predicted the overall quality of life (Q1) as well as the general health satisfaction (Q2). The exploratory factor analysis was used to identify the underlying variables that explain the pattern of correlation within the items and to examine the structure of WHOQOL-BREF. Leaving Q1 and Q2, 24 items underwent an exploratory factor analysis using the principle component method and orthogonal varimax rotation procedure. Factor loadings of 0.40 or above were interpreted as being meaningful. The extraction method was set up over eigenvalues $>1$.

The discriminant validity was determined via a variance analysis by a comparison of three groups, divided on the basis of the total MBI score. Values of $p<0.01$ was considered as statistically significant. These statistical methods have been reported in previous WHOQOL publications [19-21].

\section{RESULTS}

\section{Socio-demographic results}

Analysis was conducted on a total of 750 individuals. Three hundred and ninety-six (52.8\%) respondents were male, and the mean age was 62.4 years (range, 12-93 years). The number of each disability type was as follows: $448(59.7 \%)$ people with brain lesions and 399 (40.3\%) with physical disability. The $36.2 \%$ of the respondents were registered in grade II of a six-grade disability rating system, in which grade I indicates the most severe grade and grade VI relates to a mild disability determined by official standards (Fig. 1). 


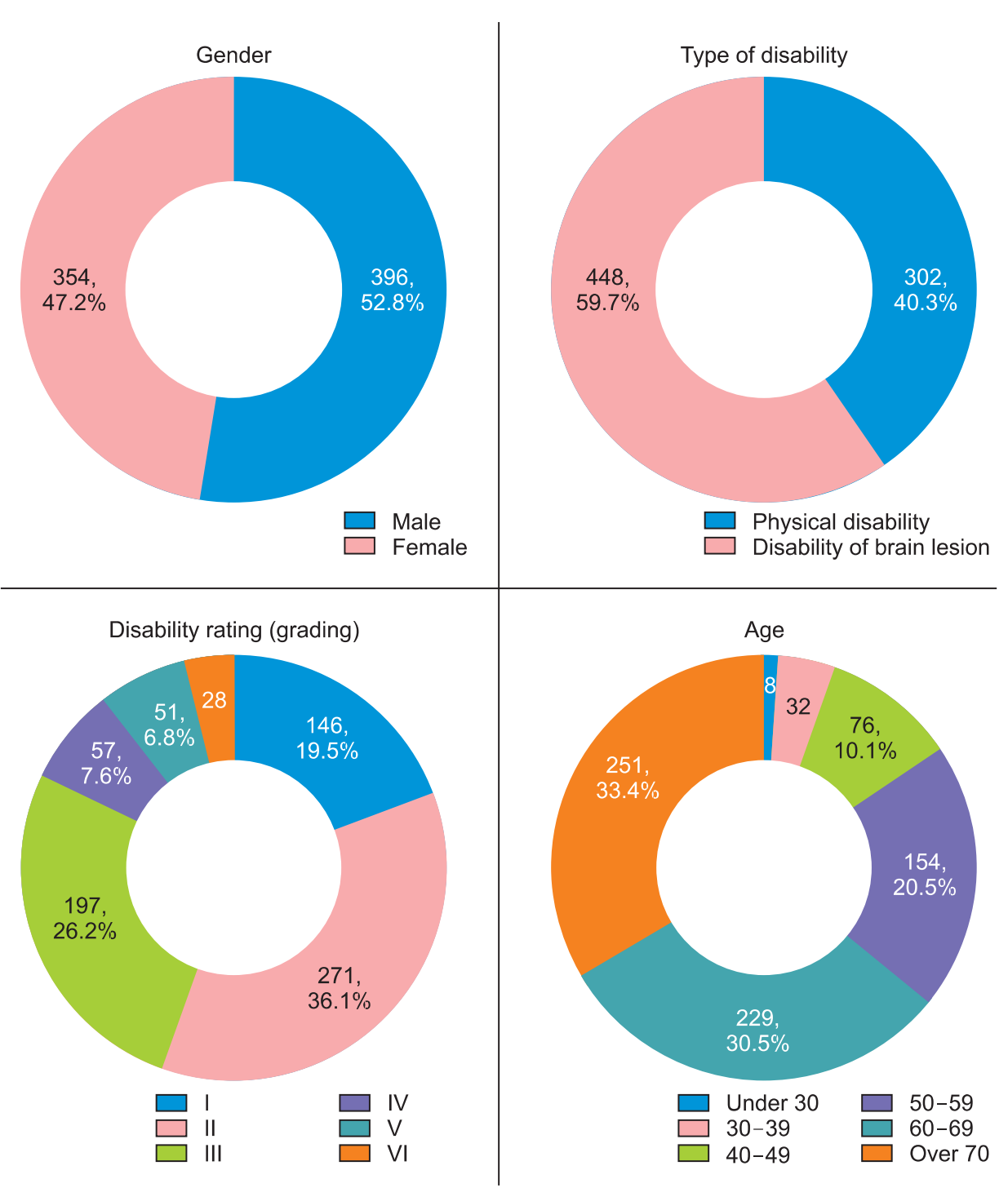

Fig. 1. Sociodemographic characteristics of the total sample $(\mathrm{n}=750)$.

\section{Internal consistency}

Cronbach's $\alpha$ value for the total score was 0.839 . The values for the physical, psychological, social relationships, and environmental domains were $0.773,0.746$, 0.849 , and 0.792 , respectively. The result reflects the acceptable internal consistency within all four domains (Table 1).

\section{Construct validity}

\section{Domain to domain correlations}

In the total sample, the correlation between each domain ranged from 0.539 to 0.717 . All correlations were moderate; the highest correlation ranged between the psychological and physical domains (0.717) while the lowest correlation was between the social and physical
Table 1. Cronbach's $\alpha$ for the WHOQOL-BREF domains

\begin{tabular}{lc}
\hline & Cronbach's $\alpha$ \\
\hline Physical & 0.773 \\
\hline Psychological & 0.746 \\
Social relationships & 0.849 \\
Environmental & 0.792 \\
Total & 0.839 \\
\hline WHOQOL, World Health Organization Quality of Life \\
Assessment.
\end{tabular}

domains (0.539) (Table 2).

\section{Item to domain correlations}

The item-domain correlation showed a significant correlation with their original domains (Table 2). Correlation 
coefficients for the physical domain ranged from 0.505 to 0.804 , from 0.586 to 0.783 for the psychological domain, from 0.745 to 0.823 for the social domain, and from 0.606 to 0.712 for the environmental domain. Q1 correlated most strongly with the psychological domain and weekly correlated with the social and environmental domains. Q2 correlated most strongly with the physical domain.

A multiple regression analysis of the domain scores with Q1 and Q2 was performed. As Q1 used for the dependent variable, the physical, psychological, and environmental domains were found to make a significant contribution. The psychological domain made the strongest contribution (unstandardized coefficient $\mathrm{B}=0.065$ ). This variance accounted for $43.7 \%$ of the total variance of the overall quality of life. When Q2 was used for the dependent variable, the physical and psychological domains were found to make a significant contribution primarily with the physical domain (unstandardized coefficient $\mathrm{B}=0.081$ ). The physical and psychological domains together explain $46.2 \%$ of the total variance for health satisfaction (Table 3 ).

Table 2. Domain-to-domain and item-to-domain intercorrelations of the WHOQOL-BREF

\begin{tabular}{|c|c|c|c|c|c|c|}
\hline Question and domain & Q1 & Q2 & Physical & Psychological & Social relationships & Environmental \\
\hline Physical & - & - & - & - & - & - \\
\hline Psychological & - & - & 0.717 & - & - & - \\
\hline Social & - & - & 0.561 & 0.597 & - & - \\
\hline Environmental & - & - & 0.608 & 0.661 & 0.539 & - \\
\hline Q1 & - & - & 0.584 & 0.602 & 0.428 & 0.501 \\
\hline Q2 & 0.587 & - & 0.652 & 0.602 & 0.413 & 0.459 \\
\hline Q3 & -0.434 & -0.511 & -0.744 & -0.415 & -0.323 & -0.323 \\
\hline Q4 & -0.320 & -0.429 & -0.649 & -0.339 & -0.279 & -0.244 \\
\hline Q5 & 0.425 & 0.447 & 0.509 & 0.783 & 0.437 & 0.519 \\
\hline Q6 & 0.462 & 0.404 & 0.499 & 0.774 & 0.461 & 0.556 \\
\hline Q7 & 0.354 & 0.336 & 0.438 & 0.690 & 0.381 & 0.457 \\
\hline Q8 & 0.361 & 0.400 & 0.435 & 0.508 & 0.298 & 0.612 \\
\hline Q9 & 0.331 & 0.275 & 0.299 & 0.402 & 0.274 & 0.701 \\
\hline Q10 & 0.475 & 0.497 & 0.692 & 0.675 & 0.400 & 0.586 \\
\hline Q11 & 0.426 & 0.430 & 0.486 & 0.696 & 0.370 & 0.487 \\
\hline Q12 & 0.407 & 0.334 & 0.446 & 0.478 & 0.343 & 0.712 \\
\hline Q13 & 0.325 & 0.314 & 0.457 & 0.536 & 0.364 & 0.701 \\
\hline Q14 & 0.376 & 0.389 & 0.493 & 0.557 & 0.401 & 0.704 \\
\hline Q15 & 0.380 & 0.420 & 0.694 & 0.560 & 0.394 & 0.575 \\
\hline Q16 & 0.307 & 0.233 & 0.505 & 0.335 & 0.310 & 0.301 \\
\hline Q17 & 0.488 & 0.566 & 0.804 & 0.608 & 0.508 & 0.495 \\
\hline Q18 & 0.446 & 0.517 & 0.766 & 0.605 & 0.539 & 0.473 \\
\hline Q19 & 0.513 & 0.559 & 0.661 & 0.753 & 0.596 & 0.531 \\
\hline Q20 & 0.449 & 0.408 & 0.555 & 0.612 & 0.823 & 0.483 \\
\hline Q21 & 0.272 & 0.316 & 0.373 & 0.405 & 0.745 & 0.372 \\
\hline Q22 & 0.290 & 0.253 & 0.398 & 0.392 & 0.806 & 0.422 \\
\hline Q23 & 0.322 & 0.272 & 0.345 & 0.363 & 0.424 & 0.663 \\
\hline Q24 & 0.253 & 0.206 & 0.313 & 0.300 & 0.364 & 0.606 \\
\hline Q25 & 0.317 & 0.278 & 0.466 & 0.402 & 0.425 & 0.669 \\
\hline Q26 & -0.402 & -0.408 & -0.482 & -0.586 & -0.319 & -0.285 \\
\hline
\end{tabular}

WHOQOL, World Health Organization Quality of Life Assessment. $\mathrm{p}<0.01$. 
Table 3. Regression analysis of the WHOQOL-BREF domains on the overall question scores

\begin{tabular}{|c|c|c|c|}
\hline Domains & Unstandardized coefficient B & 95\% CI for regression coefficient & p-value ${ }^{\text {a) }}$ \\
\hline \multicolumn{4}{|l|}{ Q1 } \\
\hline Physical & 0.047 & $0.033-0.063$ & $<0.001$ \\
\hline Psychological & 0.065 & $0.047-0.084$ & $<0.001$ \\
\hline Environmental & 0.020 & $0.006-0.033$ & 0.005 \\
\hline \multicolumn{4}{|l|}{ Adjusted $\mathrm{r}^{2}=0.437$} \\
\hline \multicolumn{4}{|l|}{ Q2 } \\
\hline Physical & $\mathbf{0 . 0 8 1}$ & $0.067-0.095$ & $<0.001$ \\
\hline Psychological & 0.060 & $0.042-0.078$ & $<0.001$ \\
\hline Adjusted $\mathrm{r}^{2}=0.462$ & & & \\
\hline
\end{tabular}

Table 4. Exploratory factor loadings of items in the WHOQOL-BREF with four factors

\begin{tabular}{|lcccc}
\hline \multicolumn{1}{c}{ Domains and items (no. of original items) } & Factor 1 & Factor $\mathbf{2}$ & Factor 3 & Factor 4 \\
\hline Opportunities for acquiring new information/skills (13) & $\mathbf{0 . 6 4 9}$ & 0.090 & 0.116 & 0.299 \\
\hline Spiritually/religion/personal beliefs (6) & $\mathbf{0 . 7 0 7}$ & 0.112 & 0.346 & 0.044 \\
\hline Energy and fatigue (10) & $\mathbf{0 . 6 6 4}$ & 0.374 & 0.138 & 0.141 \\
\hline Positive feelings (5) & $\mathbf{0 . 7 0 8}$ & 0.133 & 0.370 & -0.044 \\
\hline Recreation/leisure activities (14) & $\mathbf{0 . 6 4 5}$ & 0.148 & 0.167 & 0.251 \\
\hline Financial resources (12) & $\mathbf{0 . 5 6 7}$ & 0.158 & 0.025 & $\mathbf{0 . 4 2 2}$ \\
\hline Body image and appearance (11) & $\mathbf{0 . 6 1 2}$ & 0.260 & 0.162 & 0.056 \\
\hline Freedom, physical safety and security (8) & $\mathbf{0 . 5 6 9}$ & 0.267 & -0.028 & 0.230 \\
\hline Thinking, learning, memory (7) & $\mathbf{0 . 5 9 3}$ & 0.110 & 0.308 & 0.042 \\
\hline Physical environment (9) & $\mathbf{0 . 5 5 0}$ & -0.030 & -0.46 & $\mathbf{0 . 5 4 0}$ \\
\hline Mobility (15) & $\mathbf{0 . 5 2 1}$ & 0.347 & 0.175 & 0.246 \\
\hline Dependence on medical substances/aids (4) & -0.045 & $\mathbf{- 0 . 7 5 4}$ & -0.046 & -0.067 \\
\hline Pain and discomfort (3) & -0.110 & $\mathbf{0 . 8 0 1}$ & -0.061 & -0.146 \\
\hline Work capacity (18) & 0.318 & $\mathbf{0 . 5 6 1}$ & $\mathbf{0 . 4 5 4}$ & 0.076 \\
\hline Activities of daily living (17) & 0.330 & $\mathbf{0 . 5 7 9}$ & $\mathbf{0 . 4 2 3}$ & 0.125 \\
\hline Negative feelings (26) & -0.168 & $-\mathbf{0 . 5 6 4}$ & -0.224 & -0.014 \\
\hline Personal relationships (20) & 0.298 & 0.269 & $\mathbf{0 . 6 8 5}$ & 0.148 \\
\hline Social support (22) & 0.091 & 0.059 & $\mathbf{0 . 7 2 0}$ & 0.326 \\
\hline Sexual activity (21) & 0.177 & 0.140 & $\mathbf{0 . 5 8 0}$ & 0.152 \\
\hline Self-esteem (19) & $\mathbf{0 . 4 1 3}$ & $\mathbf{0 . 4 3 7}$ & $\mathbf{0 . 5 3 2}$ & 0.104 \\
\hline Sleep and rest (16) & 0.087 & 0.213 & $\mathbf{0 . 3 6 4}$ & 0.251 \\
\hline Home environment (23) & 0.191 & 0.081 & 0.233 & $\mathbf{0 . 7 2 5}$ \\
\hline Health and social care: accessibility and quality (24) & 0.097 & 0.064 & 0.250 & $\mathbf{0 . 7 0 4}$ \\
\hline Transport (25) & 0.199 & 0.245 & 0.256 & $\mathbf{0 . 5 9 2}$ \\
\hline Percent of variance after rotation & 20.388 & 14.129 & 11.296 & 9.480 \\
\hline WQ
\end{tabular}

WHOQOL, World Health Organization Quality of Life Assessment.

\section{Factor analysis}

The exploratory factor analysis yielded four factors in the WHOQOL-BREF, accounting for $55.29 \%$ of the vari- ability (Table 4).

Eleven items were loaded on the first factor, which explained $20.4 \%$ of the rotation variance. The first factor is 
Table 5. Comparison of the WHOQOL-BREF with the score of MBI

\begin{tabular}{|c|c|c|c|c|c|}
\hline \multirow[b]{2}{*}{ Domain } & \multicolumn{3}{|c|}{ K-MBI } & \multirow[b]{2}{*}{ F-value } & \multirow[b]{2}{*}{ p-value } \\
\hline & $\begin{array}{c}\text { Total or severe } \\
\text { dependence }(n=132)\end{array}$ & $\begin{array}{c}\text { Moderate } \\
\text { dependence }(n=178)\end{array}$ & $\begin{array}{c}\text { Slight } \\
\text { dependence }(n=430)\end{array}$ & & \\
\hline \multicolumn{6}{|l|}{ WHOQOL-BREF } \\
\hline Physical & $13.8(4.44)$ & $16.5(4.09)$ & $20.0(4.50)$ & 117.5 & $<0.001$ \\
\hline Psychological & $13.5(4.33)$ & $14.4(3.83)$ & $17.0(3.87)$ & 52.3 & $<0.001$ \\
\hline Social & $7.2(2.43)$ & $8.2(2.11)$ & $8.9(1.90)$ & 31.6 & $<0.001$ \\
\hline Environmental & $19.0(4.88)$ & $19.4(4.70)$ & $21.4(4.86)$ & 17.6 & $<0.001$ \\
\hline
\end{tabular}

Values are presented as mean (standard deviation).

WHOQOL, World Health Organization Quality of Life Assessment; K-MBI, Korean version of Modified Barthel Index.

considered to be a psychological component. Four items (Q5, Q6, Q7, and Q11) were originally included under the psychological domain, but five (Q8, Q9, Q12, Q13, and Q14) were in the environmental domain, and two (Q10, Q15) were in the physical domain. However, considering that the factor loaded above 0.40 were interpreted as being significant, item numbers 9 and 12 also could be cross-loaded in their original domains.

Five items were loaded on the second factor with $14.1 \%$ of rotation variance. The second factor is considered to be a physical component. Four items (Q3, Q4, Q17, and Q18) were originally included under the physical domain, but item number 26 was originally in the psychological domain.

The third factor represents the social component, in which five items were loaded, explaining $11.3 \%$ of the rotation variance. Three (Q20, Q21, and Q22) items were originally included in the social domain. Item number 19 was originally in the psychological domain and also demonstrated a significant result $(0.413,0.437)$ with the first and second factors. Item number 16 , originally in the physical domain, showed a weaker loading which was not significant with all of the four factors, but had a trend of relation with the third factor.

The last factor accounted for $9.5 \%$ of the rotation variance; three items were loaded, and all of them originally represented the environmental components.

The total cumulative variance explained by these four factors was $55.29 \%$.

\section{Discriminant validity}

For exploring the discriminant validity, a comparison of each domain utilizing the respondent's functional ability was performed. The MBI was divided into three groups in degrees of 'total or severe dependence,' 'moderate dependence', and 'slight or no dependence'; indicating an MBI score of ' $0-53$ ', ' $54-80$ ', and ' $81-100$ ', respectively. The variance analysis (Table 5) indicated that there were highly significant changes across the MBI groups with the WHOQOL-BREF domains $(\mathrm{p}<0.001)$. This represents that if the functional independency is higher the quality of life is also good. This trend is also observed among all four domains of WHOQOL-BREF.

\section{DISCUSSION}

The aim of this study is to investigate the validity and reliability of the Korean version WHOQOL-BREF in people with physical impairment. The results of our study revealed that WHOQOL-BREF is valid and reliable in this group. It has good internal consistency, construct validity as well as discriminant validity.

Cronbach's $\alpha$ value used for assessing internal consistency showed high scores in the range of 0.746 to 0.849 for each domain. These values are comparable with the previous study of the Korean version study of WHOQOLBREF, which indicated a range of 0.584 to 0.777 , implying that the social domain reveals relatively low values [6].

The construct validity was significantly high, showing that the domain to domain correlation of range was 0.539 to 0.717 . However, even if the domains are highly related, the correlation coefficients are not so high as to suggest that the domains are measuring the same concept. As also expected, this could explain the variance between the four domains [22].

Further, all individual items were best correlated with their conceptual original domains. The overall quality of life mostly contributed to the psychological domain, 
whereas health satisfaction primarily contributed to the physical domain. These are different results compared to the Korean version WHOQOL and WHOQOL-BREF study conducted in healthy subjects and medical patients. In the previous study, the physical domain came out to be the largest contributor in the overall quality of life [6]. However, the study of Polish and Norwegian participants showed a similar result to this study for the main contributing factor $[20,22]$. In summary, the physical and psychological domains can explain the participant's quality of life and health satisfaction better than the environmental and social domains.

For the comparison of each domain score with the functional ability measured by MBI, the discrimination validity meant a higher MBI score correlated with a higher WHOQOL-BREF. These results demonstrate that WHOQOL-BREF scores are highly responsive to the clinical condition of the respondent's functional ability and can distinguish well between them. This result is also supported by the previous result in the disease group of dementia or traumatic brain injury $[23,24]$. Our study could also be meaningful in that the self-recorded WHOQOL-BREF strongly correlates with the functional ability rated by health care providers.

As part of the construct validation, the exploratory factory analysis (EFA) of the total sample was conducted. Four factors were detected, explaining $55.29 \%$ of the total cumulative variance. Ten items were included as different factors from their original domain. Among the ten items, 'financial resources', 'physical environment', and 'self-esteem' were cross-loaded on the original domain. It is worthy to note that eleven items were loaded on the psychological component. 'Opportunities for acquiring new information/skills, 'recreation/leisure activities', 'financial resources,' 'freedom, physical safety and security', and 'physical environment' were originally included in the environmental domain and 'energy and fatigue' and 'mobility' were originally included in the physical domain. The 'sleep and rest' item was not significantly loaded on any factor, but had the highest loading in the social domain.

Although the previous Korean version study of WHOQOL-BREF did not perform EFA, similar studies conducted in other countries revealed various EFA results. The concomitant feature of the previous study was that even if the study was performed on the general population or specific disease entity, the WHOQOL-BREF has a fourfactor solution [9]. In the previous study of Taiwan, which searched the quality of life of traumatic spinal cord injury using WHOQOL-BREF, ten items showed correlations with other domains [19]. In a Norwegian WHOQOL-BREF study among 4,000 respondents, seven items were shown to have multicollinearity effects, indicating an overlapping of content structure, particularly in the psychological and environmental domains [22].

The result of the factor analysis could be explained with the Korean socio-cultural background. Considering the respondents of our study were people with disabilities living in communities, the psychological property coming from the environmental and physical aspects would be maximized. The social attitudes of poor understanding of disability and developing social welfare system could have a relation as to why the five environmental factors were included in the psychological domain in this study. This cross-cultural variance was also suggested in a previous study of the Korean version WHOQOL-BREF, interpreting that the reason of social, independence and spiritual domains was found to be less important [6]. Consequently, it could carefully suggest that the expansion of the Korean social-welfare system on financial support, environmental improvement, safety and opportunity for social activity could influence the psychological aspect of quality of life in people with physical impairment.

\section{Study limitation}

The selection of the subjects has several limitations in this study. There might be a selection bias in that the recruitment was conducted by the CBR project. Lack of stratification in socio-demographic variances exists, especially in the ratio between physical disability and brain lesion. Response bias could also reflect the findings because the data is based on self-reported questionnaires; moreover, testing the retest reliability is absent. Considering the subjects were those with registered disability in the chronic stage, further study is needed, including a study on physically impaired patients in the acute and subacute stages.

The EFA revealed the necessity for further confirmatory factor analysis. To verify construct validity, the previous study of the Korean WHOQOL-BREF in the general population conducted confirmatory factor analysis. Due 
to different statistical methods, it is difficult to compare the pervious data with this study.

Despite these limitations, this study has significance as the first study of registered disability, not limiting the subjects in a particular disease. In this study, the Korean WHOQOL-BREF was valid and reliable in people with physical impairment. This could be a significant pilot study for a further well-designed and stratified study about people with such disabilities.

The large sample size could be the strength of this study. Considering the known ratio of each health condition [25], the outcome could be carefully applied in physical impairments related with stroke, musculoskeletal disorder, fractures, brain injury, and osteoarthritis.

In conclusion, the Korean WHOQOL-BREF is valid and reliable to measure the quality of life with good internal consistency, construct validity and discriminant validity among people with physical impairments living in a community. WHOQOL-BREF demonstrated higher internal consistency than that in the general Korean population. The overall quality of life was mostly related to the psychological domain, and health satisfaction mainly contributed to the physical domain. The item-domain correlation and exploratory factor analysis showed a structural similarity with the original 4-domain model. Higher functional independency rated by MBI correlated well with the WHOQOL-BREF. These results indicate that this questionnaire could be useful in assessing the quality of life in Korean people who are registered with physical disability or disabilities associated with brain lesions.

\section{REFERENCES}

1. Employment Development Institute. Statistics on the disabled in 2011. Seongnam: Employment Development Institute; 2011.

2. Kim SW, Lee WS, Shin JB, You S, Lee SK, Yun DS, et al. Severity of disability and quality of life in handicapped persons in welfare facility and home in Goyang city. J Korean Acad Rehabil Med 2008;32:443-8.

3. Campolina AG, Pinheiro MM, Ciconelli RM, Ferraz MB. Quality of life among the Brazilian adult population using the generic SF-8 questionnaire. Cad Saude Publica 2011;27:1121-31.

4. The WHOQOL Group. The World Health Organization Quality of Life Assessment (WHOQOL): position pa- per from the World Health Organization. Soc Sci Med 1995;41:1403-9.

5. The WHOQOL Group. The World Health Organization Quality of Life Assessment (WHOQOL): development and general psychometric properties. Soc Sci Med 1998;46:1569-85.

6. Min SK, Kim KI, Lee CI, Jung YC, Suh SY, Kim DK. Development of the Korean versions of WHO Quality of Life scale and WHOQOL-BREF. Qual Life Res 2002;11:593-600.

7. Development of the World Health Organization WHOQOL-BREF quality of life assessment. The WHOQOL Group. Psychol Med 1998;28:551-8.

8. Skevington SM, Lotfy M, O'Connell KA; WHOQOL Group. The World Health Organization's WHOQOLBREF quality of life assessment: psychometric properties and results of the international field trial. A report from the WHOQOL group. Qual Life Res 2004;13:299310.

9. Yao $\mathrm{G}, \mathrm{Wu} \mathrm{CH}$. Factorial invariance of the WHOQOL-BREF among disease groups. Qual Life Res 2005;14:1881-8.

10. World Health Organization. World report on disability. Geneva: World Health Organization; 2011.

11. Australian Institute of Health and Welfare. Disability and disability services in Australia: based on an extract of Australia's welfare, 2005. Canberra: Australian Institute of Health and Welfare; 2006.

12. Leung SO, Chan CC, Shah S. Development of a Chinese version of the Modified Barthel Index: validity and reliability. Clin Rehabil 2007;21:912-22.

13. Chan SW, Chiu HF, Chien WT, Goggins W, Thompson D, Hong B. Predictors of change in health-related quality of life among older people with depression: a longitudinal study. Int Psychogeriatr 2009;21:1171-9.

14. Shah S, Vanclay F, Cooper B. Improving the sensitivity of the Barthel Index for stroke rehabilitation. J Clin Epidemiol 1989;42:703-9.

15. Jorgensen HS, Nakayama H, Raaschou HO, Vive-Larsen J, Stoier M, Olsen TS. Outcome and time course of recovery in stroke. Part I: Outcome. The Copenhagen Stroke Study. Arch Phys Med Rehabil 1995;76:399-405. 16. Sulter G, Steen C, De Keyser J. Use of the Barthel index and modified Rankin scale in acute stroke trials. Stroke 1999;30:1538-41.

17. Wade DT, Hewer RL. Functional abilities after stroke: 
measurement, natural history and prognosis. J Neurol Neurosurg Psychiatry 1987;50:177-82.

18. Jorritsma W, de Vries GE, Dijkstra PU, Geertzen JH, Reneman MF. Neck Pain and Disability Scale and Neck Disability Index: validity of Dutch language versions. Eur Spine J 2012;21:93-100.

19. Jang $\mathrm{Y}, \mathrm{Hsieh} \mathrm{CL}$, Wang $\mathrm{YH}, \mathrm{Wu} \mathrm{YH}$. A validity study of the WHOQOL-BREF assessment in persons with traumatic spinal cord injury. Arch Phys Med Rehabil 2004;85:1890-5.

20. Jaracz K, Kalfoss M, Gorna K, Baczyk G. Quality of life in Polish respondents: psychometric properties of the Polish WHOQOL-Bref. Scand J Caring Sci 2006;20:25160.

21. Yao G, Chung CW, Yu CF, Wang JD. Development and verification of validity and reliability of the
WHOQOL-BREF Taiwan version. J Formos Med Assoc 2002;101:342-51.

22. Hanestad BR, Rustoen T, Knudsen O Jr, Lerdal A, Wahl AK. Psychometric properties of the WHOQOL-BREF questionnaire for the Norwegian general population. J Nurs Meas 2004;12:147-59.

23. Lucas-Carrasco R, Skevington SM, Gomez-Benito J, Rejas J, March J. Using the WHOQOL-BREF in persons with dementia: a validation study. Alzheimer Dis Assoc Disord 2011;25:345-51.

24. Chiu WT, Huang SJ, Hwang HF, Tsauo JY, Chen CF, Tsai SH, et al. Use of the WHOQOL-BREF for evaluating persons with traumatic brain injury. J Neurotrauma 2006;23:1609-20.

25. Kim SH. Research on the actual condition on disabled in 2011. Seoul: Ministry of Health \& Welfare; 2011. 